\title{
The Coloured Voice: Finding Its Place in South African Poetry
}

\author{
Kirsten Deane \\ Department of English, The University of The Western Cape, Cape Town, South Africa
}

Email address:

Kirstendeane14@gmail.com

\section{To cite this article:}

Kirsten Deane. The Coloured Voice: Finding Its Place in South African Poetry. Education Journal. Vol. 10, No. 4, 2021 , pp. $154-159$.

doi: $10.11648 /$ j.edu. 20211004.16

Received: June 29, 2021; Accepted: July 24, 2021; Published: July 29, 2021

\begin{abstract}
South African poetry has found its place in many parts of the world. Topics such as racism, discrimination and issues resulting from the past of South Africa, have all found themselves in South African literary journals and anthologies. One of the achievements of the South African poet has been finding a place for the disadvantaged group/s of South Africa, the group/s that have suffered through the past and present South Africa. However, through all the major South African journals and literary collections, the voice and life of the Coloured individual has been left out and overlooked. More importantly, this has resulted in the Coloured individuals of South Africa not knowing their place in the poetry world. More specifically, because they are not reading about their cultural power in poetry, they tend to believe that poetry is not for the Coloured culture and language. In this paper I intend to show that there has been a lack of place in poetry for the Coloured individual, and furthermore, to show that there is a place for the Coloured story and culture in poetry. As a result, what will be shown is the effect that the Coloured voice will have on South African poetry, and how it will benefit a large portion of the South African population.
\end{abstract}

Keywords: South Africa, Poetry, Coloured, Mixed Race

\section{Introduction}

The term 'Coloured' has received various reactions throughout the years of its existence. In some places, such as the United States of America, it is frowned upon to use this term to define an individual. Rather, a 'Coloured' person is thought of as somebody that is a mix of races, commonly thought of as a mix of Africans (blacks) and whites. However, in South Africa, 'Coloured' has obtained its right to be used as the term to define the unique racial group that was once looked at as being 'undefined'. As a result of being looked at as 'undefined', these individuals would be referred to as 'mixed', a term that would lead to a confused sense of identity. However, as time went on, it became obvious to an academic and writer like myself, that the Coloured identity was and is hardly present in South African literature and poetry. I embarked on a journey to not only write poetry, but to write this research paper which would explore and highlight the lack of presence of Coloured identity in poetry. I will then shed light on why and how the Coloured identity could be present in South African poetry.

\section{Poetry and Race: A Relationship}

\subsection{The Root of Coloured}

In South Africa, Coloured is the name of a race that is defined as being a combination of more than one race within the population. During the Apartheid era, races were separated and treated accordingly. Each race would have different disadvantages and the non-white races were limited in their opportunities in the academic sense and so much more. South Africa had namely four races: Blacks, Whites, Coloureds, and Indians. With Coloured becoming the defining name of a racial group, came so many other ways of life. In particular, the Coloured Culture. As the Coloured population was named and separated from the rest, they developed their own unique way of living. This was done through food, language and even ways of dress.

\subsection{Poetry Finding Its Place}

For many South Africans, writing has become a form of expression, not only to get through and cope with the struggles 
they have faced and are facing; struggles such as racism and inequality, but they have also used the art of writing to express their individual cultures and what that individuality means for their everyday life. Karen Press, a South African poet, wrote a poem dedicated to another woman, Jessie Tamboer, who sacrificed her own life because she could no longer provide for her children. This poem may give you an insight into one of the many intentions of South African poetry: to shine light on dark circumstances. Have a look at the fourth stanza:

Sometimes I cry, I

the absolute poor

I am sick to death of watching my ruin. [12]

Through writing about who they are and using language to explore their identity more than before, these individuals are able to look at themselves with true understanding, a concept which Michelle Decker uses in her work:

When poetry's sounds or organization approaches the thing they describe, when through language they transcend language's merely communicative function, poetry (and, by extension, language itself) approaches purity. [13]

Prior to my decision to write this research paper, I wrote poem that spoke to my need, as a Coloured academic, to express my everyday experience as a Coloured writer and living in a Coloured home:

My poetry wants women

My fingers have been aching and crying when I look away. They're tired.

They've been writing about the white women and their beauty, the perfections that they carry.

My paper-cut fingers want to write about the coloured women

that hang in my curls

with their legs crossed and their arms reaching across

their chest to stop the men from staring

at their breasts,

My poetry wants to bring their eyes back to meet ours.

My hands want to write about the coffee and koeksisters

that sit on our table but only on a Sunday.

About the fulfilment a coloured woman only gets from family.

I want to write about the beautiful black women that ride the taxi

with me, their voices that have more life in them than their lungs.

My hands want to write about the colourful women

I live beside and my poetry will show

us combined into a rainbow

that doesn't end.

My inspiration for this piece was my everyday surroundings and my academic history. Having been an undergraduate and a current postgraduate student at The University of The Western Cape, a university known for its hand in fighting against oppression and discrimination, I was always exposed to creative writing that explored these issues. However, while obtaining my degree in English Literature, I found that the creative pieces which we explored were mostly written by Black or White individuals. The literary pieces which we explored that had touched on Coloured identity, did so merely on the surface, which is common in current literary studies as Mohamed Adhikari states:

The current literature offers only the most superficial of attempts at analysing the essential character of Coloured identity or the social and political dynamic that informed Coloured exclusivism. [9]

I started wondering, where are the coloured creatives? The coloured writers? Yes, there are the few here and there whose work gets explored and noticed, but why are there not more? Why are we not explored in the creative academia? These questions, and so much more, are what I intend to explore in this paper.

\section{Finding a Place}

\subsection{The Common South African Poet}

Interestingly, when I began to think about writing this paper, I decided to simply search up 'top South African poets'. Here are the top results:

Keorapetse Kgositsile. (1938-2018)

Antjie Krog.

Breyten Breytenbach

Joan Hambidge

Mzwakhe Mbuli

Roy Campbell (1901-1957)

David Wright (1920-1994)

Ingrid Jonker (1933-1965)

Lebogang Mashile

Mongane Wally Serote

What was interesting about the results was that 1) it was mostly men and 2) it was mostly Black and White individuals. As a young, Coloured writer, I find myself not only yearning to read work from the coloured community, but furthermore, I yearn to read work by the female-coloured community. The minority that is a big part of the coloured culture.

\subsection{What Does South African Poetry Seek}

In this paper I intend to show that the voices of South African poetry is majority that of the White and Black culture. Furthermore, I will show that the nature of South African poetry does have a place for the Coloured culture and voice.

C. J. D Harvey wrote a paper titled "Local colour in South African Poetry". In this paper, Harvey explores the idea that South African poetry has a desire to create and embrace the distinct South African culture through the medium of poetry:

In South Africa, as in other Dominions and newly-developed and culturally self-conscious countries, there is a great desire to produce and develop a 'national 'culture embracing distinctive local forms, especially in poetry and painting. [1]

As Harvey states, South African poetry aims to embrace distinct local forms that refer to the different cultures of South Africa. Harvey's statement is true, as can be seen in well-known poetry. However, there is a local form that South African poetry has been lacking: the Coloured form. 


\section{South African Purpose Poetry}

In her paper "Faces of Commitment: Poetry from South Africa" Adrienne Rich presents us with well-known pieces of poetry that explore life in South Africa. She emphasizes the fact that South African poetry has created a bridge between political struggles and poetry:

Mainstream North American culture tries to tell us that art and politics do not mix, that the struggle for social justice hampers the poetic imagination. Across this continent and throughout the world, nonetheless, poets are writing who accept no such separation, and political struggles draw on the resources of poetry. [3]

Rich then chose specific pieces of South African poetry that would demonstrate this. The pieces she chose focused on land, community, and the different forms it comes in, in South Africa. Rich believes that the power of South African poetry lies in the idea that it can create a sense of understanding and connection between the different races and cultures of South Africa: "The poems by ANC women draw me physically into the core of Black South African experience as not even the most devastating statistics can do." [3]

However, because of the history of South Africa and the colonisation that took place, South African poetry tended to, and still does in many ways, be written without focusing on the individuality of the culture of South African people but was influenced by past circumstances. Mashudu Churchill Mashige touches on this fact:

Written poetry in English has been shaped largely y, and has reacted to, colonial experience, which, because of its imperialistic nature, brought with it a great sense of cultural dispossession on the past of the indigenous population. [10] Romanus N. Egudu also zooms in on this in his book 'Modern African poetry and the African predicament.':"Thus the African retains his old self but adds on to it something borrowed from the imported culture." [14]

\subsection{Poetry Using Place}

Rich emphasizes the power that poetry has to create understanding and empathy. She highlights the idea that the poetry which she has read creates an understanding for her of the Black South African experience. This is true as many well-known South African poems explore this idea. Take for instance, Childhood in Soweto, a poem by Lerato Kumalo. This piece explores the circumstances of the communities that Black children must endure while growing up. Have a look at the first stanza:

There are no playgrounds

no parks

but plenty dust

children compete

cars bicycles hungry mongrels

narrow streets and garbage

there is no childhood

in Soweto. [3]

The poem creates a clear image of the horrifying conditions that the Black South African has to live in. This is not a unique subject in the South African poetry community. Black South Africans have taken it upon themselves to make this topic a priority in the craft of writing poetry. This stands as a powerful movement for South Africa: making the conditions known and drawing attention to it. However, I wonder about the other conditions of the other communities in South Africa that could, and would, if given the opportunity, give an insight into the struggles and lives of many other South Africans. There are multiple struggles and horrifying conditions in the Coloured community, but these are barely looked at in literature. Circumstances from the past has changed but the painful ones are hardly touched. Kelwyn Sole mentions this in his paper:

In recent written literature, however, there is less evidence of a revitalized consciousness seeking to confront the country's changed political and social circumstances than in these other forms of expression. [11]

The Coloured community presents its own struggles and fears that reflect the realistic struggles of South Africa. Martin Amberger explores this in her paper "The Situation of the Coloureds in South Africa.":

What is alarming is the immense crime rate among the coloureds, which is highest in the Western Cape Province, a region mostly inhabited by this population group. In the residential areas of the coloureds, burglary and theft rates are markedly higher than elsewhere, and coloured people are twice as likely to die a violent death as blacks. [4]

As Amberger explores the circumstances and conditions of the Coloured community, it is made clear that the Coloured community is in the centre of troubling crimes and this results in children being exposed to the crimes, inevitably beginning to think that such circumstances are normal. As the Coloured communities experience these crimes of South Africa first-hand, it is surely obvious these communities could be writing poetry that gives an insight into the harsh conditions that South Africans face. The Coloured voice should be given a chance to express their circumstances, just as the Black voice has. Granting them this opportunity will result in South Africa being explored from a different and fresh perspective through poetry.

\subsection{Finding the Poetry}

It is true that not every poet will be a great poet, that is a fact one has to accept. However, how are we to find the great poets without giving them the opportunity to show their greatness? There are many outreach programs that take place in Cape Town, ones such as Call 2 Care that focuses on educational outreach projects with the hope that this will help change the circumstances for those living in unhealthy and dangerous environments. Poetry has the power of giving the individual a place to express themselves vividly and honestly. In order to find the great poets, we have to provide the opportunities of learning the craft of writing to those who have not had it before - this will enable us to peel away the 'near-poets', as Harvey refers to them and find the major poets. Harvey elaborates on this:

There will, and must, of course, always be a fair number of near-poets and minor poets who keep the interest in poetry and 
the traditional forms alive and help to make the major poet's achievement possible when he comes. [1]

As Harvey states, we need to allow the near-poets to write as well. To progress in their writing so we may establish if there is a major poet in them. With regards to the subject matter of this paper, this means that Coloured communities that are not privileged, or even lucky enough to have the opportunities to learn what poetry entails, should be given that very opportunity through outreach programs and things alike. As the Coloured community is exposed to and in the centre of the harsh crimes of South Africa, they need to be given the opportunity to write about it. This will do a justice for what South Africa needs: to have its reality shown through the power of literature. This is what we may call South African literature.

\section{The Coloured Community in Language}

The Coloured community has its own unique way of doing things, and this includes speaking. The Coloured community has created its own use of language, including slang and a mixture of English and Afrikaans. This is one of the original traits of the Coloured culture. A simple example could be the term 'awe'(ah-weh) [8], used as a greeting. In the Coloured community this could also be used to show comfortability and a relationship that the two individuals using this term have. A unique way of greeting that brings across a sense of familiarity and home. What also reflects this is the term 'brah', derived from 'broer' [8], the Afrikaans word for brother, and is another term used in the Coloured communities that represents and describes the friendship between two (or more) individuals. It is clear that the Coloured community creates and uses its own type of language to show closeness and many other things that are shown through different terms. For example, the word 'bergie' (bear-ghee) [8], which is derived from the Afrikaans word 'berg' which means mountain, refers to homeless individuals that live on the streets. The Coloured community has created its own way of communication that gives this culture its originality. This is the type of language originality that poetry values. C. J. D. Harvey explores this:

But unless they write honestly and with all the originality, they are capable of, and unless they and their readers are kept constantly aware of their limitations by comparison with the best that has been and is being written, the soil that they cultivate will turn sour so that no poetry can flourish and potential poets will turn aside from its tasks or else seek a better soil elsewhere. [1]

\subsection{Coloured Language Belonging}

As Harvey states, the poet needs to focus on his/her originality and unique honesty. For the literary and poetic world, this includes the unique language of the poet. Jeremy Cronin, a well-known South African poet, shows exactly this in his piece 'Motho Ke Motho Ka Batho Babang' (A person is a person because of other people). We can see him doing this in the lines 20 to 22 :

\section{Hey! Wat maak jy daar?}

A voice from around the corner.

No, Just polishing baas. [3]

Cronin chose to use the unique language of the prisoner and the individual holding the prisoner captive. By doing this, Cronin added two unique voices to his piece that reflected the reality of the subject of the poem. They speak using the language (or slang) that they have become accustomed to using through their circumstances. Cronin's work and choice of language works to show the power of using language that is used by specific individuals and communities - it works to give us an insight into the worlds of these individuals that are a part of the subject at hand. Take for example, the term 'baas', a term which slaves of colour would use to approach their 'masters'; reflecting how language was used to show manners of communication. This reflects the ways in which language, if used in its natural, everyday form, can be used to show cultural identity. Mashudu Churchill Mashige aims to show this in his paper which focuses on identity in South African poetry: "to analyse how each putative body of poetry conceives and articulates cultural identity." [15] That being said, the Coloured language could do the same thing, if used in poetry. I decided to test this out in the following piece that I have written:

The coloured language

By Kirsten Deane

In our house, there is a certain way to say no, without moving your lips in the shape of the words.

Thank you. Mostly

A pause, a look is exchanged, and we understand each other.

Or a click of the tongue, a loud; mxm, lekker man.

I see why you are offering but it's not for me; Yah, nah.

Our language tells our visitors that they are welcome

but easily says when we want to be left alone. The coloured language says;

no, without that kind of violence.

whispers, strokes, says; sorry

and offers you a cup of rooibos tea because our mother-tongue taught us so.

You'll slurp, and swallow with a burn on your tongue

Yoh man, you could've told me it was hot

and a laugh as a goodnight because our mother-tongue taught us gratitude as joy.

With the piece above, I decided to incorporate the Coloured language/slang as moments of action. I then followed it with the meaning of that specific Coloured term in order to show how language is used to communicate in a unique manner in the Coloured household/community. As a result, one could say that the Coloured language has a romantic side, a side that tells a story in as little as two words. This proves that the Coloured language could and should be used in poetry as it has the power to help the poem tell a story.

\subsection{The Individual in South African Poetry}

Andrew Foley wrote a paper titled "A Sense of Place in Contemporary White South African English Poetry". In this 
paper, Foley explores the presence of the English-speaking South Africans' lack of sense of place, and how it presents itself in the poet's work:

And particularly to consider the ways in which recent white South African English poets have responded in their poetry to this problem. More specifically, this article will suggest that a number of poets have attempted to discover a valid sense of place for their English-speaking countrymen in the context neither of British cultural traditions nor of the African natural landscape, but rather in the context of the modern cities of South Africa. [6]

Reading Foley's paper, I found myself thinking about the effect that Apartheid had on Coloured's and the Coloured community. During the time of Apartheid, many Coloureds were forcibly removed from their homes and forced to live somewhere else by the government. More harshly, Coloured people were only allowed to be in certain places at certain times. This was determined by certain laws that the government had in place. Danita Smith explores these laws in her work:

The government also enacted "pass laws" which held that blacks had no real reason to go into municipal areas unless they were there for employment reasons and, thus, required them to have passes which could help to control their movement. Other laws were passed to restrict the types of skills blacks could practice as trades. [7]

\section{The Offering of the Coloured Voice}

Smith focuses on the Black community and their place in Apartheid in her work, however, many of the same laws applied to the Coloured community. Coloureds were not allowed to enter certain places without having a valid reason. This resulted in many Coloureds believing that their place was limited and that their identities lied only where they were allowed. Now, under a new government and having moved past the Apartheid era, the Coloured South African can find themselves anywhere they like, if their circumstances allow it. What should be prioritized in the poetry of this day and age should be how the previously limited South African (Coloureds included), now find their place in their country. How the previously limited South African writes about the cities and places that he/she were kept out of previously: experiencing the South African place for the first time. Foley explores what poetry seeks in the modern context:

In the first place, in what may be regarded as the negative form of the response, the primary focus of the poetry is on outlining the nature and extent of the problem in its modern context. [6]

If South African poetry seeks to know about the past and the way forward then the answer is simple - we need to hear from all the previously disadvantaged communities, Coloureds included.

\subsection{Coloured Culture Cluster}

Many Coloureds in the city of Cape Town, South Africa, reside in what is referred to as 'The Cape Flats', an area that is majority concrete buildings/flats. These areas are busy, loud, and dangerous. However, it holds a lot of the Coloured culture and as a result, has become a part of the Coloured identity. South African poetry tends to explore the attachment that the poet and South Africans alike, have to the natural landscape that characterizes its beautiful country. In turn, we tend to overlook the beauty that is the individual places that we call home, such as the Cape flats. Foley expands on this:

But although they have as a group clearly elected to live in the cities, any feelings of love or reverence for, or deep attachment to, these cities, have been curiously absent from any medium in which the sentiments of the group have been articulated, including poetry. Part of the reason for this may lie in the general notion that feelings of ethnic group belonging are usually associated with ideas of land or soil rather than with metropolitan areas. This would seem to hold true especially for a country like South Africa which is renowned far more for its natural features than for its urban ones. [6]

\subsection{The Coloured Home as Poetry}

As the Coloured's of Cape Town find themselves closely situated to each other in the Cape Flats, poetry finds itself there. For the Coloured community, a neighbour is regarded as a home and this translates to being comfortable all around; communication is done in a friendly manner, individuals feel comfortable enough to leave their homes in any sort of clothing. There is a clear honesty in the Coloured community, and this results in stories being shown from every corner. For the poet and writer, to witness as much cultural uniqueness and life in one place as is in the Cape Flats, would surely inspire a modern type of writing and reflect an inner working of South Africa: The Coloured community.

\section{Conclusion}

South African poetry relies on the uniqueness of the experiences of its population and how they interpret, as well as live through the struggles of the past and present. By failing to provide a place for the Coloured voice in South African poetry, the South African literary scene is overlooking the stories of a portion of its population that not only suffers but survives day in and day out. By working towards growing a place for the South African Coloured voice, we are giving new poets a chance to present themselves, and furthermore, we are giving language a chance to show itself in different forms and with different meaning. The Coloured voice is to be given a poetic opportunity to show a different side of South Africa. It becomes clear that if the Coloured individual is not given an opportunity to write about their life and place in South Africa, their identity will continue to be ambiguous and overlooked. The uniqueness of South Africa lies in its diversity of cultures, we need to allow a place for the Coloured culture as well so that this uniqueness may continue to grow and make itself present in poetry and literature. 


\section{References}

[1] Harvey, C. J. D. "Local colour in South African poetry". Theoria: A Journal of Social and Political Theory, 1955, No. 7 (1955), pp. 93-100.

[2] Kumalo, Lerato. "Childhood in Soweto."

[3] Rich, Adrienne. "Faces of Commitment: Poetry From South Africa." Crime and Social Justice, 1985, No. 24, STATE TERRORISM IN SOUTH AFRICA (1985), pp. 135-142.

[4] Amberger, Martin. "The Situation of The Coloureds in South Africa." Pp, 1-3. https://www.kas.de/c/document_library/get_file?uuid=403f 25 5d-5a29-7f20-0eaf-028a95224200\& groupI $\overline{\mathrm{d}}=25203828$ June 2021.

[5] Cronin, Jeremy. "Motho Ke Motho Ka Batho Babang".

[6] Foley, Andrew. "A Sense of Place in Contemporary White South African English Poetry." English in Africa, Oct. 1992, Vol. 19, No. 2 (Oct, 1992), pp. 35-53.

[7] Smith, Danita. "Laws from South Africa's Apartheid." Black and Education. Red and Black Ink, LLC. Web. 26 June 2021. $<$ https://searchblackandeducation.com/stories/2017/2/5/selecte d-laws-from-apartheid>
[8] Hamman, Meagan. "Your Guide to Cape Town Slang." Cape Town Magazine. Cape Town Magazine Online. n. pag. Web. $27 \quad$ May 2021. $<$ https://www.capetownmagazine.com/cape-town-slang >

[9] Adhikari, Mohamed. "Hope, Fear, Shame, Frustration: Continuity and Change in the Expression of Coloured Identity in White Supremacist South Africa, 1910-1994.” Journal of Southern African Studies, Sep. 2006, Vol. 32, No. 3 (Sep. 2006), pp. 467-487.

[10] Mashige, Mashudu Churchill. Politics and aesthetics in contemporary black South African poetry. Diss. University of Johannesburg, 1996.

[11] Sole, Kelwyn. "Bird hearts taking wing: trends in contemporary South African poetry written in English." World Literature Today 70. 1 (1996): 25-31.

[12] Hirson, Denis, ed. The Lava of This Land: South African Poetry, 1960-1996. Northwestern University Press, 1997.

[13] Decker, Michelle. "Entangled Poetics: Apartheid South African Poetry between Politics and Form." Research in African Literatures 47.4 (2016): 71-90.

[14] Egudu, Romanus N. Modern African poetry and the African predicament. Springer, 1978.

[15] Mashige, Mashudu Churchill. Identity, culture and contemporary South African poetry. Diss. Rand Afrikaans University, 2004. 